\title{
Is the Quality of Neurosurgical Literature Improving?
}

\author{
James Harrop, MD \\ Thomas Jefferson University \\ Mitchell Maltenfort, PhD \\ Thomas Jefferson University
}

Follow this and additional works at: https://jdc.jefferson.edu/jhnj

Part of the Neurology Commons

\section{Let us know how access to this document benefits you}

\section{Recommended Citation}

Harrop, MD, James and Maltenfort, PhD, Mitchell (2010) "Is the Quality of Neurosurgical Literature Improving?," JHN Journal: Vol. 7 : Iss. 1 , Article 6.

DOI: https://doi.org/10.29046/JHNJ.007.1.001

Available at: https://jdc.jefferson.edu/jhnj/vol7/iss1/6

This Article is brought to you for free and open access by the Jefferson Digital Commons. The Jefferson Digital Commons is a service of Thomas Jefferson University's Center for Teaching and Learning (CTL). The Commons is a showcase for Jefferson books and journals, peer-reviewed scholarly publications, unique historical collections from the University archives, and teaching tools. The Jefferson Digital Commons allows researchers and interested readers anywhere in the world to learn about and keep up to date with Jefferson scholarship. This article has been accepted for inclusion in JHN Journal by an authorized administrator of the Jefferson Digital Commons. For more information, please contact: JeffersonDigitalCommons@jefferson.edu. 


\section{Is the Quality of Neurosurgical Literature Improving?}

\author{
James S. Harrop, MD, Mitchell G. Maltenfort, PhD \\ Department of Neurological Surgery, Thomas Jefferson University, Philadelphia, PA
}

\section{Abstract}

Introduction: The advent of evidence-based medicine has resulted in higher quality journal manuscripts in numerous medical disciplines. However, the impact in the neurosurgical literature has not been reported.

Objective: To quantify the impact of evidence-based medicine on the quality of articles published in the Neurosurgery literature.

Methods: Articles published in the journal Neurosurgery (founded in 1977) were reviewed for 1978, 1988, 1998, and 2008. Each decade's sample was classified as therapeutic, diagnostic and prognostic based on a published system for determining level of evidence.

Results: 438 articles were reviewed. Articles not considered included any published under the heading "Case Report" (automatically Level IV evidence) and articles which otherwise did not directly look at patient outcome (i.e, cadaver or animal studies). The rate of Level I studies held steady at $4.5-6.0 \%$. Level II evidence increased steadily from no articles in 1978 to $40.6 \%$ in 2008 . The increases in Level I and II article publications was statistically significant $(\mathrm{p}<0.001)$. Concurrently, Level IV articles decreased in rate (81.8\% in 1978 to $42.4 \%$ in 2008), while Level III articles remained fairly constant $(9.8 \%-13.6 \%)$. The largest category of Level II studies was prognostic, and the largest

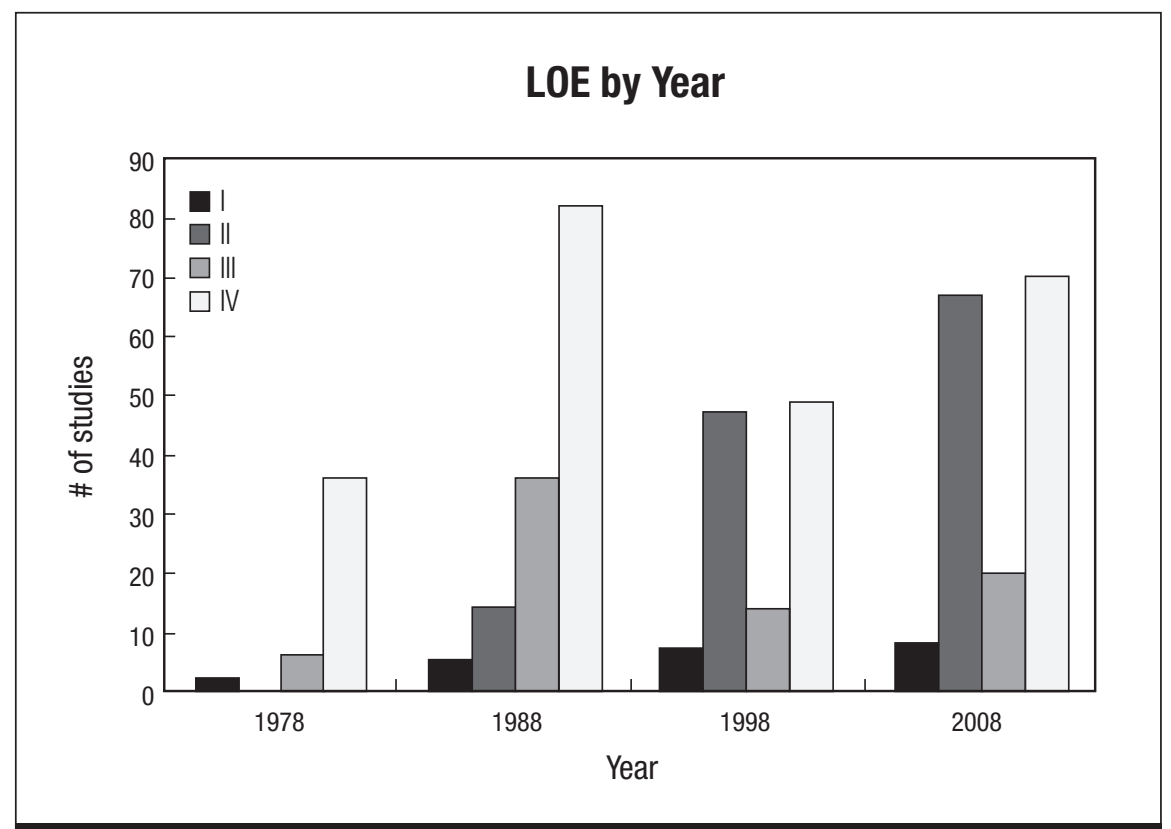

\section{Figure 1}

Shows the relationship between article Level of Evidence and year of publication. The rate of Level I studies held steady at 4.6-5.0\%. Level II evidence increased steadily from no articles in 1978 to $40.6 \%$ of the published articles in 2008. The increase in the rate of publication of articles Level 1 and 2 was statistically significant $(p<0.001$, chi-square test). Concurrently, the Level IV articles decreased in rate ( $81.8 \%$ in 1978 to $42.4 \%$ in 2008), while the Level III remained fairly constant $(9.8 \%-13.6 \%)$. category for both Level III and IV studies was therapeutic. Among study types, the most dramatic increase was in the rate of prognostic studies ( $15.8 \%$ to $43.6 \%)$. Only $1 \%$ of all articles were economic analyses.

Conclusion: The quality of neurosurgical literature has progressively improved over the last several decades. It is unclear how much of that is due to expanded activity in randomized, clinical trials or other Level I evidence as no significant increases were observed in Level I articles during the study period (1978-2008). Much of the literature improvement may be explained by the increase in retrospective, prognostic studies as neurosurgeons take advantage of years of accumulated data. The lack of any articles on economic and decision analyses suggests that the neurosurgical community has not yet studied the effect of costs in detail.

\section{Introduction}

Evidence-based medicine (EBM) has been established to define the quality of literature in medical specialties. It has resulted in an increase in quality of medical literature overall. However, over the last several decades there has been an emphasis by editors and professional societies on the importance of obtaining the highest quality of medical literature through reporting evidence-based medicine levels. This manuscript reviews the last three decades of a major neurosurgical journal in an attempt to identify if there have been significant changes in terms of quality as defined by contemporary evidence-based medicine schema. Specifically, evaluating if there has been an overall improvement in the quality of neurosurgery literature as defined by EBM grading schemes.

\section{Methods}

A retrospective review of articles published in the journal Neurosurgery was performed. Each article was evaluated through a detailed assessment of the abstract and manuscript if necessary. All manuscripts were classified or graded based on an evidence-based medicine categorization as described by Wright et al $(2003)^{1}$. This review was modeled after similar evaluation of literature quality in Journal of Bone and Joint Surgery. ${ }^{2}$ 


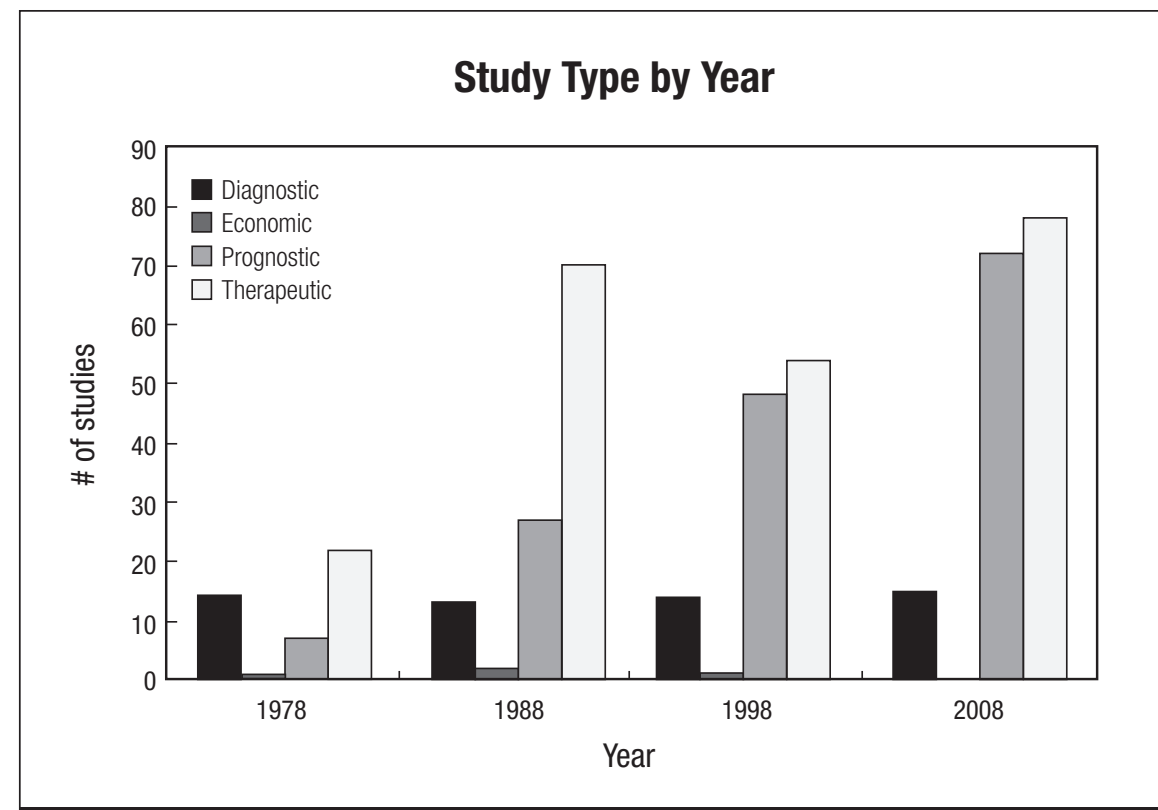

\section{Figure 2}

Shows the relationship between article type and year of publication. Among study types, the most dramatic increase was in the rate of prognostic studies (15.8\% to 43.6\%). The number of diagnostic studies remains constant at 13-15 articles per sampled year.

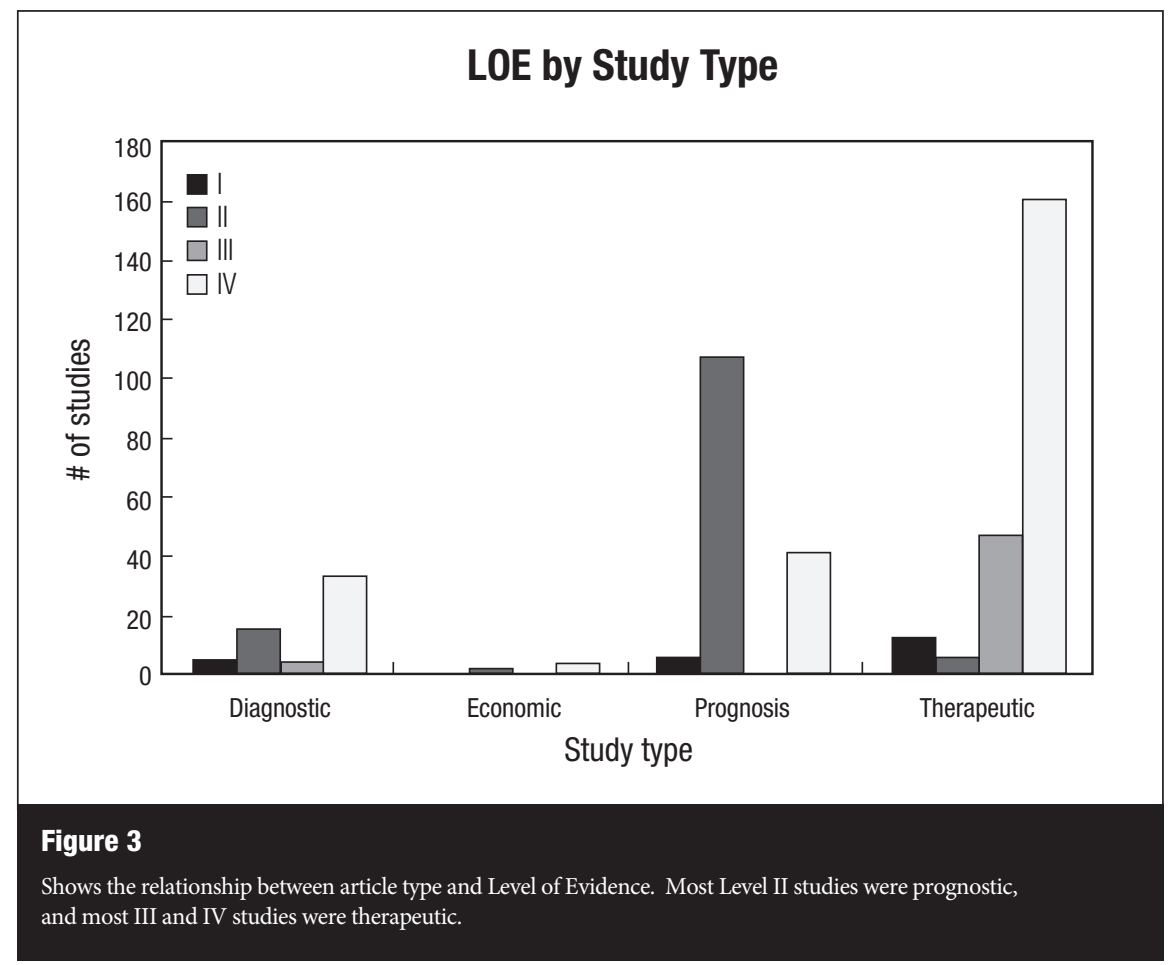

Manuscripts were selected from the years 19782008, specifically selecting the represented years 1978, 1988, 1998 and 2008. Each manuscript was reviewed such to categorize the quality of the literature based on the five-level EBM grading used by the Journal of Bone and Joint Surgery. ${ }^{1}$
Due to the small number of manuscripts the literature was further subanalyzed into "good" literature class I and II compared to the less rigid literature of class III and IV.

\section{Results}

438 articles were individually reviewed categorized and graded based on EBM guidelines. Articles excluded from analysis included any published under the heading "Case Report" (automatically Level IV evidence) and articles which otherwise did not directly look at patient outcome (i.e, cadaver or animal studies).

The relationship between article Level of Evidence and year of publication noted that the Level I studies had a consistent and steady rate between 4.6-5.0\%. Level II evidence increased steadily from no articles in 1978 to $40.6 \%$ of the published articles in 2008. The increase in the rate of publication of articles Level I and II was statistically significant ( $p<0.001$, chisquare test). Concurrently, the Level IV articles decreased in rate $(81.8 \%$ in 1978 to $42.4 \%$ in 2008), while the Level III remained fairly constant (9.8\%-13.6\%). (Figure 1)

The relationships between article type and year of publication noted the most dramatic increase was in the rate of prognostic studies (15.8\% to $43.6 \%)$. The number of diagnostic studies remains constant at 13-15 articles per sampled year. The number of therapeutic papers increases sharply after 1978 but then remains relatively constant. Only $4 / 438$ papers were economic analyses: 1 in 1978, 2 in 1988, and 1 in 1998. Excluding economic papers, because the small count will distort results, the relationship between year and publication type was statistically significant $(\mathrm{p}<0.001$, chisquare test; Figure 2).

The association between article type and Level of Evidence (1-4) illustrated that the largest category of Level II studies was prognostic, and the largest category for both Level III and IV studies was therapeutic. Again excluding the small number of economic papers, the relationship between year and publication type was statistically significant $(\mathrm{p}<0.001$, chisquare test). Except for prognostic studies, level IV studies (case series) were the most numerous for each article type (diagnostic, economic or therapeutic). (Figure 3)

The rate of "good" articles (Level I or II) varies within the three main categories (diagnostic, prognostic or therapeutic) over time. Both prognostic and diagnostic studies improved over time, prognostic studies reaching a plateau 


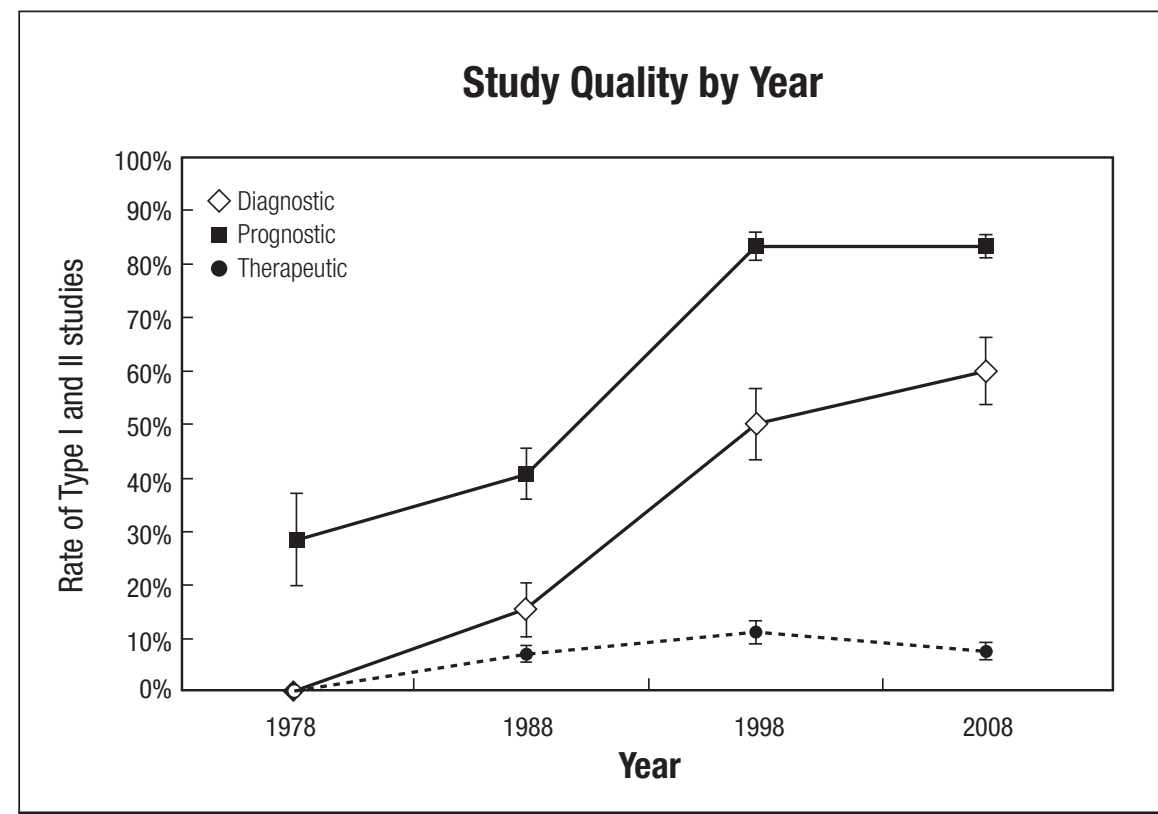

Figure 4

Rate of good studies increases within diagnostic and prognostic groups.

in 1998 and diagnostic studies trailing but continuing to climb. There were no good-quality therapeutic studies in 1978, and from 1988-2008 the rate of good articles remained fairly constant. Multivariate logistic regression indicates that the rate of good articles was associated with both year and type of article ( $\mathrm{p}<0.001$ for each). (Figure 4)

\section{Discussion}

The practice of medicine over time has undergone significant changes and alterations such to optimally treat patients and society.
The analysis of quality of care and quality of literature has come to the forefront over the last several decades. Specifically, significant attention has been placed on determining best medical practices. In order to maximize patient outcomes, the best or optimum practices must be determined. The goal of publications is to summarize and promote further advances in medical treatment.

This manuscript was designed to analyze the influence of time on publishing higher quality evidence-based medicine theories such to determine if there has been improvement in the quality of literature based on these categorization schemes. There has been a significant shift towards improvement in the quality of evidence in the medical literature, but the body of neurosurgery literature still demonstrates a relative paucity of Level I manuscripts. The inherent difficulties with obtaining Level I evidence in surgical practice and the attempts to achieve higher quality manuscripts were represented in the Level II literature which increased from $0 \%$ in 1978 to $40.6 \%$ in 2008 of all published manuscripts. Over this period, there was a progressive increase in treatment prognosis with a concurrent decrease in the number of diagnostic and economic related articles. These parallel trends may reflect the increasing number of retrospective studies (level II prognostic ${ }^{1}$ ) as more long-term data becomes available.

In conclusion, surgical literature has been following trends of other academic journals in that there has been a progressive improvement in the quality of articles according to evidencebased medicine standards. While the Level I evidence had only minimal gains, there were substantial gains in Level II literature likely reflecting both the genuine efforts toward achieving higher quality, evidence-based manuscripts and the inherent difficulties of delivering the same.

\section{References}

1. Wright JH, Swiontkowski MF, Heckman JD (2003). Introducing levels of evidence to the journal. J Bone Joint Surg Am. 85: 1-3.

2. Hazlik S, Mahabir RC, Baynosa RC, Khiabani KT (2009). Levels of evidence in research published in The Journal of Bone and Joint Surgery (American Volume) over the last thirty years. J Bone Joint Surg Am. 91: 425-428.

\section{Brain power}

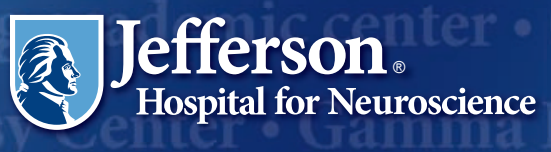

1-800-JEFF-NOW

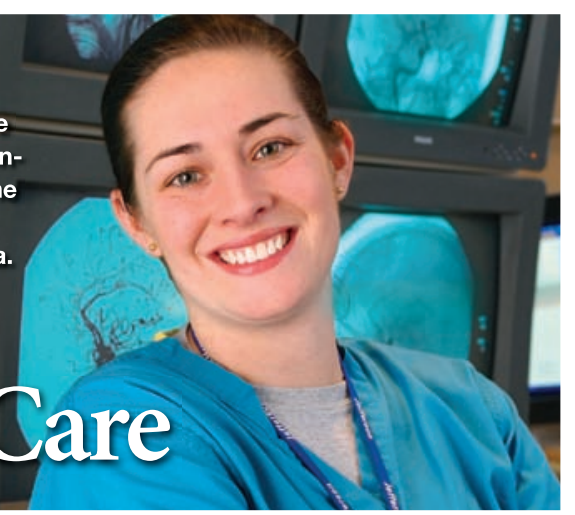

The Jefferson Acute Stroke Center is Joint Commissioncertified and has among the highest number of stroke discharges in Pennsylvania. (a) 